TITLE:

\title{
Photo-induced lattice softening of excited-state VO2
}

$\operatorname{AUTHOR}(\mathrm{S})$ :

Hada, Masaki; Okimura, Kunio; Matsuo, Jiro

\section{CITATION:}

Hada, Masaki ...[et al]. Photo-induced lattice softening of excited-state VO2. APPLIED PHYSICS LETTERS 2011, 99(5): 051903.

\section{ISSUE DATE:}

2011-08-01

URL:

http://hdl.handle.net/2433/160635

\section{RIGHT:}

Copyright 2011 American Institute of Physics. This article may be downloaded for personal use only. Any other use requires prior permission of the author and the American Institute of Physics. The following article appeared in APPLIED PHYSICS LETTERS 99, 051903 (2011) and may be found at http://link.aip.org/link/?apl/99/051903 


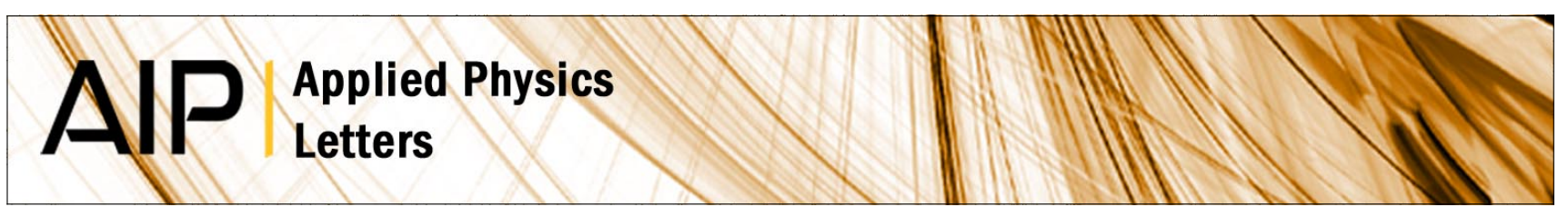

\section{Photo-induced lattice softening of excited-state VO2}

Masaki Hada, Kunio Okimura, and Jiro Matsuo

Citation: Appl. Phys. Lett. 99, 051903 (2011); doi: 10.1063/1.3621900

View online: http://dx.doi.org/10.1063/1.3621900

View Table of Contents: http://apl.aip.org/resource/1/APPLAB/v99/i5

Published by the American Institute of Physics.

\section{Related Articles}

Effect of the electrode materials on the resistive switching of Ti4O7

Appl. Phys. Lett. 101, 053502 (2012)

Bipolar resistive switching characteristics of Al-doped zinc tin oxide for nonvolatile memory applications Appl. Phys. Lett. 101, 052901 (2012)

Orbital symmetry induced conductance switching in a graphene nanoribbon heterojunction with different edge hydrogenations

Appl. Phys. Lett. 101, 053101 (2012)

Strongly coupled phase transition in ferroelectric/correlated electron oxide heterostructures

Appl. Phys. Lett. 101, 042902 (2012)

Electrical transition of $(3,3)$ carbon nanotube on patterned hydrogen terminated $\mathrm{Si}(001)-2 \times 1$ driven by electric field

J. Appl. Phys. 111, 123717 (2012)

\section{Additional information on Appl. Phys. Lett.}

Journal Homepage: http://apl.aip.org/

Journal Information: http://apl.aip.org/about/about_the_journal

Top downloads: http://apl.aip.org/features/most_downloaded

Information for Authors: http://apl.aip.org/authors

\section{ADVERTISEMENT}

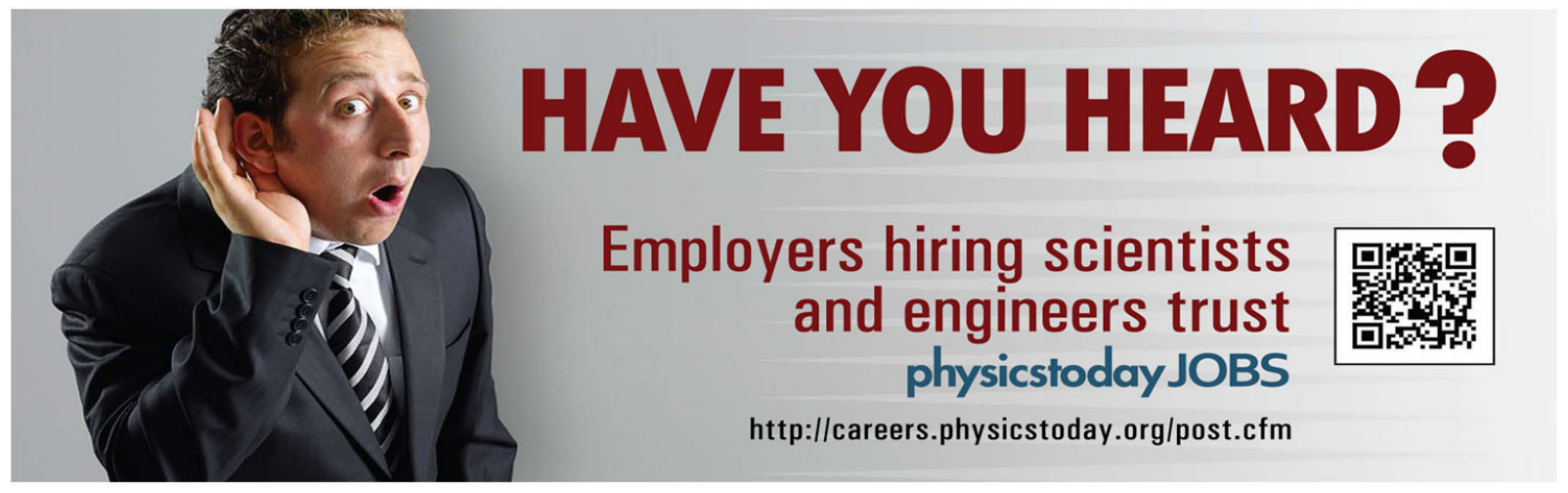




\title{
Photo-induced lattice softening of excited-state $\mathrm{VO}_{2}$
}

\author{
Masaki Hada, ${ }^{1, a), b)}$ Kunio Okimura, ${ }^{2}$ and Jiro Matsuo ${ }^{1, c)}$ \\ ${ }^{1}$ Quantum Science and Engineering Center, Kyoto University, Uji 611-0011, Japan \\ ${ }^{2}$ Faculty of Engineering, Tokai University, Hiratsuka, Kanagawa 259-1292, Japan
}

(Received 6 June 2011; accepted 14 July 2011; published online 1 August 2011)

\begin{abstract}
In this letter, we demonstrated the photoexcitation of metallic phase vanadium dioxide $\left(\mathrm{VO}_{2}\right)$ with time-resolved $\mathrm{x}$-ray diffraction measurements. Through the photoexcitation, the metallic phase $\mathrm{VO}_{2}$ transitioned to the similar transient state, which was presented in the insulator to metal phase transition in the time-scale of $\sim 10 \mathrm{ps}$. This transient state was accessed only by the photoexcitation and not through further thermal excitation. The presence of the transient state could be an important factor in any further application of the phase transition phenomena. (C) 2011 American Institute of Physics. [doi:10.1063/1.3621900]
\end{abstract}

The metal-insulator transition in vanadium dioxide $\left(\mathrm{VO}_{2}\right)$ has potential applications for switching devices, actuators, and memories and has received considerable attention in fundamental studies on phase transitions. ${ }^{1,2}$ Recent progress in femtosecond time-resolved techniques enabled the observation of phase transition phenomena by inducing a photonic excitation in the femtoseconds-to-picoseconds time-scale. Several studies on time-resolved optical, ${ }^{3}$ teraherz, ${ }^{4}$ soft $\mathrm{x}$-ray spectroscopic, ${ }^{5}$ and crystallographic ${ }^{6,7}$ measurements have revealed the dynamics of phase transitions in these materials. In particular, ultrafast time-resolved x-ray diffraction (XRD) and electron diffraction enables direct observation of atomic motion during the phase transition. We used time-resolved XRD to observe the photo-induced structural phase transition in an epitaxially grown $\mathrm{VO}_{2}$ thin film.

At the critical temperature $\left(T_{c}\right)$ of $\sim 340 \mathrm{~K},{ }^{8} \mathrm{VO}_{2}$ undergoes a metal-to-insulator transition. This change in electrical properties is accompanied by a structural transition from a monoclinic phase (the M-phase) below $T_{c}$ to a metallic rutile phase (the R-phase) above $T_{c}$. Previous studies have indicated an intermediate or transient state of $\mathrm{VO}_{2}$ between the $\mathrm{M}$ and $\mathrm{R}$ phases. This is considered to be a deformed monoclinic ${ }^{9}$ or vibronic excited state. ${ }^{10,11} \mathrm{VO}_{2}$ is photoexcited to the transient state within 1-10 ps; the M-phase lattice rapidly transforms into the R-phase structure. However, the atoms in the unit cell and, the unit cell itself, become disordered or vibrate around the center of the rutile coordinates, and the excited state is abated by coupling with an isotropic thermal phonon within $\sim 100$ ps. In this paper, we report the observation of a similar transient state formed by photoexcitation of the thermally excited R-phase $\mathrm{VO}_{2}$ in the time scale of $\sim 10 \mathrm{ps}$.

A highly (010)-oriented $\mathrm{VO}_{2}$ film (280 nm thick) was epitaxially grown on a $c-\mathrm{Al}_{2} \mathrm{O}_{3}(0001)$ substrate at a temperature of $673 \mathrm{~K}^{12,13}$ The lattice parameters of $\mathrm{VO}_{2}$ in the $\mathrm{M}$ and $\mathrm{R}$ phases were measured using static XRD with $\mathrm{Cu} \mathrm{K} \alpha$ $\mathrm{X}$-ray radiation $(\lambda=0.154 \mathrm{~nm})$ and were found to be $a=0.5759 \mathrm{~nm}, b=0.4518 \mathrm{~nm}, c=0.5363 \mathrm{~nm}, \beta=122.3^{\circ}$

\footnotetext{
a)Electronic mail: masaki.hada@mpsd.cfel.de.

${ }^{b)}$ Present address: Max Planck Research Department for Structural Dynamics at the University of Hamburg, Center for Free Electron Laser Science, DESY, Notkestrasse 85, 22607 Hamburg, Germany.

${ }^{c}$ Electronic mail: matsuo@nucleng.kyoto-u.ac.jp.
}

(space group: $\mathrm{P} 2 / \mathrm{C}$ ), ${ }^{14}$ and $a=b=0.4528 \mathrm{~nm}, c=0.2860 \mathrm{~nm}$ (space group: $\left.\mathrm{P} 4_{2} / \mathrm{mnm}\right),{ }^{15}$ respectively. The Bragg angles of the (020) plane in the $\mathrm{M}$ and $\mathrm{R}$ phases were $39.86^{\circ}$ and $39.77^{\circ}$, respectively. The integrated intensity increased by a factor of 1.3-1.6 in the phase transition. The critical heating temperature was $339 \mathrm{~K}$.

The time-resolved XRD measurements were performed in air using a laser plasma-induced $\mathrm{x}$-ray source of $\mathrm{Cu} \mathrm{K} \alpha_{1}$ and $\mathrm{K} \alpha_{2}$ radiations at $1 \mathrm{kHz}$, which were generated by focusing a millijoule femtosecond laser onto a rotating copper target in He ambient. The experimental setup is shown in detail in Ref. 11. The $\mathrm{VO}_{2}$ sample was loaded onto a thermal heater which was maintained in the temperature range of 322-372 K. The $\mathrm{VO}_{2}$ film was photoexcited using an 800 -nm-wavelength femtosecond optical pulse. The area excited by the optical pulse had an ellipsoidal shape of $1.9 \times 2.2 \mathrm{~mm}$ and was larger than the x-ray-probed area $(0.8 \mathrm{~mm}$ horizontal and $1.5 \mathrm{~mm}$ vertical). The intensity of the pumping pulse was $8.5 \mathrm{~mJ} / \mathrm{cm}^{2}$ $\left(\sim 1.6 \times 10^{21}\right.$ carriers $\left./ \mathrm{cm}^{3}\right)$, which was higher than the phase transition threshold $\left(6-7 \mathrm{~mJ} / \mathrm{cm}^{2}\right),{ }^{6,7}$ but much lower than the single-shot damage threshold $\left(63 \mathrm{~mJ} / \mathrm{cm}^{2}\right){ }^{6}$

Typical $\mathrm{K} \alpha_{1}$ and $\mathrm{K} \alpha_{2}$ XRD lines from $\mathrm{VO}_{2}(020)$ planes at $322 \mathrm{~K}$ and $372 \mathrm{~K}$ were obtained in time delays from -50 to 300 ps (Figs. 1(a) and 1(b)). XRD lines in the negative delay time agreed well with the lines from the unperturbed $\mathrm{M}$ and $\mathrm{R}$ phases. For the positive delay times, the XRD lines showed a shift in the Bragg angle, increase or decrease in intensity, and broadening of the full width at half-maximum (FWHM). Figure 2 shows the changes in the integrated intensity of the diffraction lines as a function of delay time in the temperature range $322-372 \mathrm{~K}$. The Bragg peak position, integrated intensity, and FWHM were derived from the double-peak Gaussian fitting curve. The states of $\mathrm{VO}_{2}$ at these temperatures corresponded to the $\mathrm{M}(322 \mathrm{~K})$ and $\mathrm{R}$ phases (341 and $372 \mathrm{~K}$ ), respectively. Generally, the Bragg peak position of XRD lines depends on the Laue function, i.e., the size of the unit cell, and the integrated intensity depends on the positions or the ordering of the atoms in the unit cell. At all temperatures, the Bragg angles of the XRD shifted toward lower angles within about $25 \mathrm{ps}$. The integrated intensities of the XRD lines at 322 and $338 \mathrm{~K}$ decreased by $70 \%-80 \%$ in about 15 ps and gradually increased by about 1.1-1.4 times in $\sim 100$ ps (Fig. 2). 


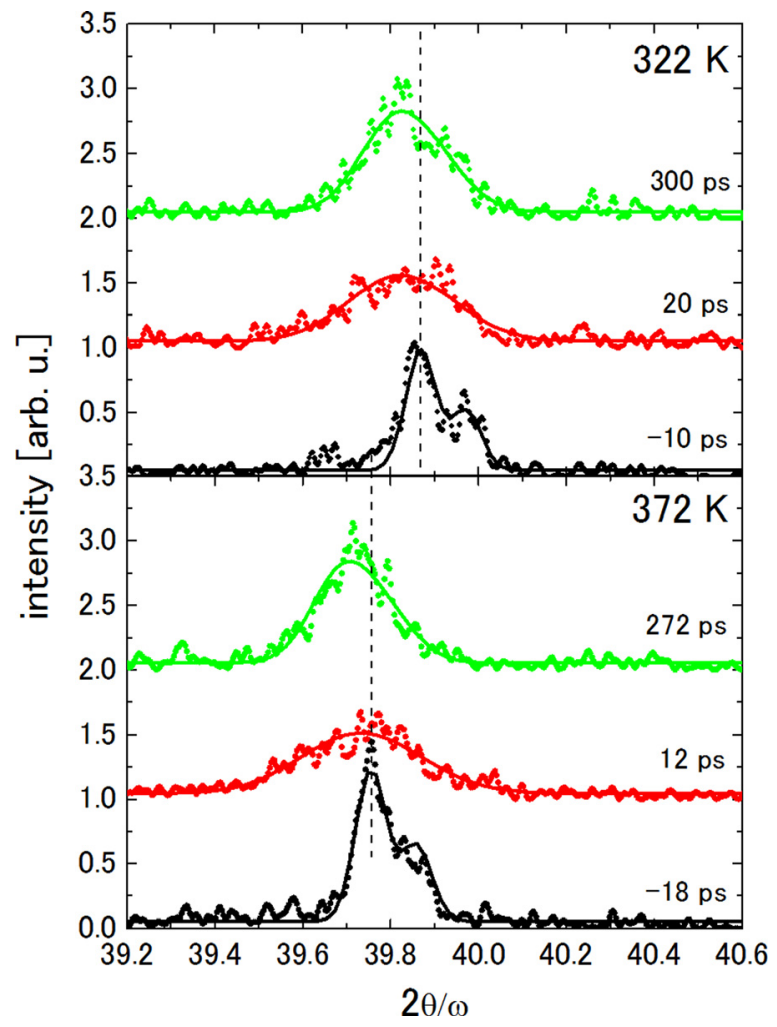

FIG. 1. (Color online) Typical spectra of time-resolved XRD lines from the (020) plane of $\mathrm{VO}_{2}$ sample at (a) $322 \mathrm{~K}$ and (b) $372 \mathrm{~K}$. The solid lines are double-peak Gaussian fitting curves. The vertical broken lines indicate the Bragg angles for a negative delay time.

The changes in XRD lines at the temperatures of 322 and $338 \mathrm{~K}$ were indicative of the insulator-to-metal phase transition in $\mathrm{VO}_{2}$; the Bragg angle was higher $(2 \theta=39.86-$ $39.82^{\circ}$ ) for the negative delay time and shifted toward a lower angle $\left(2 \theta=39.78-39.75^{\circ}\right)$ at 25 ps after photoexcitation. The integrated intensity of the XRD lines decreased in the delay time of $\sim 15 \mathrm{ps}$ and increased in $\sim 100 \mathrm{ps}$. The decrease in integrated intensity in $\sim 15 \mathrm{ps}$ suggested the transient state of $\mathrm{VO}_{2}$, i.e., disordering or fluctuation of the $\mathrm{V}$ atoms around the rutile coordinates would result in a reduced integrated intensity of the XRD lines. This transient state would gradually decay and transform into the R-phase in $\sim 100$ ps (Ref. 11). The schematic view of the metal-insula-

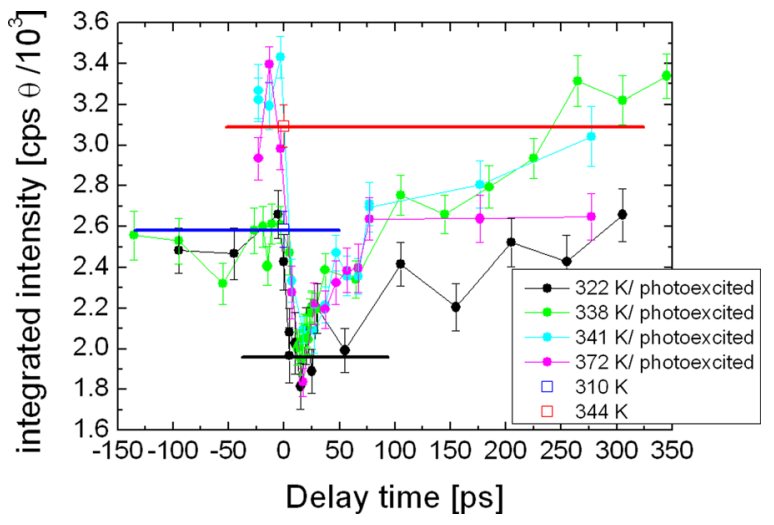

FIG. 2. (Color online) The change in integrated intensity of the (020) XRD lines in temperature range $322-372 \mathrm{~K}$. The horizontal red, blue, and black lines show the integrated intensity of R-phase, M-phase and transient state, respectively.

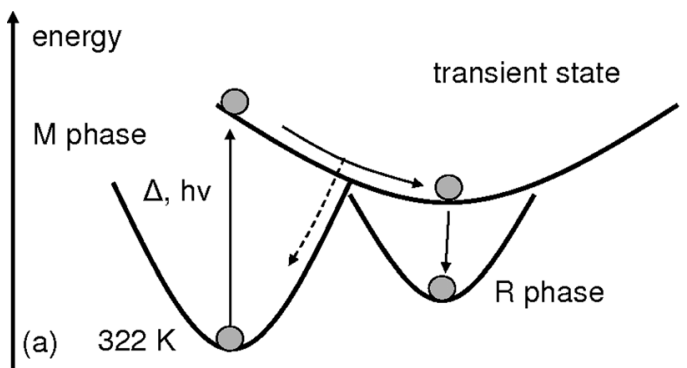

V-V separation

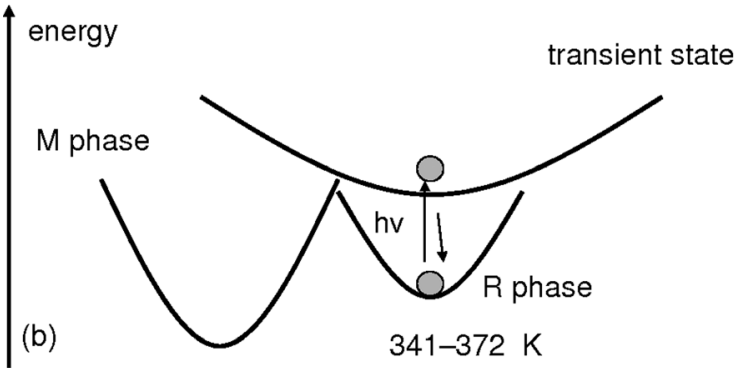

V-V separation

FIG. 3. Schematic diagrams of (a) the insulator-to-metal phase transition of $\mathrm{VO}_{2}$ : the M-phase transitions to R-phase by photo and thermal excitation through transient state (solid lines). When the excitation energy is lower than the phase transition threshold, $\mathrm{VO}_{2}$ cannot transform from M-phase to $\mathrm{R}$-phase (broken line); (b) photo-induced softening of the metal phase $\mathrm{VO}_{2}$. The transient state can be accessed from R-phase by photoexcitation. The $\mathrm{y}$-axes are energy and $\mathrm{x}$-axes are the $\mathrm{V}-\mathrm{V}$ separation of $(010)$ lattice plane.

tor phase transition of the $\mathrm{VO}_{2}$ thin film (see Fig. 3(a)) was consistent with previously reported results. ${ }^{9-11}$ It is noteworthy that the Bragg peak positions and integrated intensities of the XRD lines at 341 and $372 \mathrm{~K}$ showed a similar tendency as at 322 and $338 \mathrm{~K}$. The integrated intensity of the XRD lines decreased by photoexcitation in $\sim 15$ ps to about $50 \%$, almost the same as the films photoexcited at 322 and $338 \mathrm{~K}$. The structure reverted to the R-phase again in $\sim 100$ ps. $\mathrm{VO}_{2}$ was already in R-phase at the temperatures of 341 and $372 \mathrm{~K}$ and should not transform anymore; however, the decrease in integrated intensity suggested disordering or fluctuation of the $\mathrm{V}$ atoms around the rutile coordinates, i.e., the thermally excited $\mathrm{VO}_{2}$ underwent a transformation into the transient state through photoexcitation. The transient state of $\mathrm{VO}_{2}$ was not achieved by thermal excitation of the R-phase, but by the perturbation of the electron distribution and the electron-lattice interaction in the $\mathrm{VO}_{2},{ }^{16}$ i.e., photoexcitation of a small fraction of electrons produced a large modification in the $\mathrm{VO}_{2}$ lattice. In the schematic diagram of the photoexcitation of the thermally excited $\mathrm{VO}_{2}$ film (Fig. 3(b)), the transient state of $\mathrm{VO}_{2}$ appeared very unstable and the potential surface of the transient state has broadened.

In conclusion, using time-resolved XRD measurements, we investigated the transient state induced by weak photoexcitation in a $\mathrm{VO}_{2}$ thin film. $\mathrm{VO}_{2}$ transformed from the $\mathrm{M}$ to the $\mathrm{R}$ phase through the transient state within a time scale of a few picoseconds, and a similar transient state was obtained by photoexcitation of the thermally excited R-phase. The transient state of the $\mathrm{VO}_{2}$ film was related to the electronelectron and electron-lattice interactions. The results also suggest that time-resolved XRD is a promising method for 
exploring as-yet-unknown phenomena in various material systems. As a further application, it is interesting to note that because $\mathrm{VO}_{2}$ can be structurally photo-modulated in the metallic phase, it can be used as an electronic switching device that is controlled optically on the $100 \mathrm{ps}$ time-scale.

This work was partially supported by Core Research for Evolutional Science and Technology (CREST) of the Japan Science and Technology Agency (JST). The authors would like to acknowledge the discussions with Y. Hontani, T. Seki, and T. Aoki at Kyoto University and H. Zia and D. Mazurenko at Max Planck Research Department of Structural Dynamics, and thank R. Manory of editassociates.com for helping in preparing this material for publication.

${ }^{1}$ S. Chen, H. Ma, X. Yi, H. Wang, X. Tao, M. Chen, X. Li, and C. Ke, Infrared Phys. Technol. 45, 239 (2004).

${ }^{2}$ H. Coy, R. Cabrera, N. Sepúlveda, and F. E. Fernández, J. Appl. Phys. 108, 113115 (2010).
${ }^{3}$ M. F. Becker, A. B. Buckman, R. M. Walser, T. Lépine, P. Georges, and A. Brun, Appl. Phys. Lett. 65, 1507 (1994).

${ }^{4}$ C. Kübler, H. Ehrke, R. Huber, R. Lopez, A. Halabica, R. F. Haglund, Jr., and A. Leitenstorfer, Phys. Rev. Lett. 99, 116401 (2007).

${ }^{5}$ A. Cavalleri, M. Rini, H. H. W. Chong, S. Fourmaux, T. E. Glover, P. A. Heimann, J. C. Kieffer, and R. W. Schoenlein, Phys. Rev. Lett. 95, 067405 (2005)

${ }^{6}$ A. Cavalleri, Cs. Tóth, C. W. Siders, and J. A. Squier, Phys. Rev. Lett. 87, 237401 (2001).

${ }^{7}$ P. Baum, D.-S. Yang, and A. H. Zewail, Science 318, 788 (2007).

${ }^{8}$ F. J. Morin, Phys. Rev. Lett. 3, 34 (1959).

${ }^{9}$ K. Okimura, J. Sakai, and S. Ramanathan, J. Appl. Phys. 107, 063503 (2010).

${ }^{10}$ S. Lysenko, A. J. Rua, V. Vikhnin, J. Jimenez, F. Fernandez, and H. Liu, Appl. Surf. Sci. 252, 5512 (2006).

${ }^{11}$ M. Hada, K. Okimura, and J. Matsuo, Phys. Rev. B 82, 153401 (2010).

${ }^{12}$ K. Okimura and J. Sakai, Jpn. J. Appl. Phys. 48, 045504 (2009).

${ }^{13}$ K. Okimura, N. Ezreena, Y. Sasakawa, and J. Sakai, Jpn. J. Appl. Phys. 48, 065003 (2009).

${ }^{14}$ G. Andersson, Acta Chem. Scand. 10, 623 (1956).

${ }^{15}$ S. Westman, Acta Chem. Scand. 15, 217 (1961).

${ }^{16}$ A. Cavalleri, M. Rini, and R. W. Schoenlein, J. Phys. Soc. Jpn. 75, 011004 (2006). 